\title{
ARTICLE
}

Animal Models

\section{Long-acting CCK analogue NN9056 lowers food intake and body weight in obese Göttingen Minipigs}

\author{
Berit Ø. Christoffersen ${ }^{1} \cdot$ Rikke Bjerring Skyggebjerg $^{1} \cdot$ Anne Bugge $^{1} \cdot$ Rikke Kaae Kirk $^{1} \cdot$ Bill Vestergaard $^{1}$. \\ Henriette Kold Uldam ${ }^{2} \cdot$ Johannes Josef Fels $\mathbb{D}^{2} \cdot$ Charles Pyke $^{1} \cdot$ Ulrich Sensfuss ${ }^{2} \cdot$ Annika Sanfridson $^{1}$. \\ Trine Ryberg Clausen ${ }^{1}$
}

Received: 3 November 2018 / Revised: 16 March 2019 / Accepted: 5 April 2019 / Published online: 7 June 2019

(c) The Author(s), under exclusive licence to Springer Nature Limited 2019. This article is published with open access

\begin{abstract}
Background/Objectives Cholecystokinin (CCK) is a regulator of appetite and energy intake in man. The aim of this study was to determine the effect of NN9056, a long-acting CCK-1 receptor-selective CCK analogue, on food intake and body weight (BW) in obese Göttingen Minipigs.

Subjects/Methods Tolerability of NN9056 and acute effects on food intake, pancreas histology, amylase and lipase levels were assessed in lean domestic pigs in doses up to $100 \mathrm{nmol} / \mathrm{kg}(n=3-4)$. Subsequently, obese Göttingen Minipigs were treated subcutaneously (s.c.) once daily for 13 weeks with vehicle, NN9056 low dose (regulated from 5 to 2 nmol/kg) or NN9056 high dose $(10 \mathrm{nmol} / \mathrm{kg})(n=7-8)$. Food intake was measured daily and BW twice weekly. At the end of the treatment period, an intravenous glucose tolerance test (IVGTT) and a 24-h exposure profile was obtained. Data are mean \pm SD.

Results The acute studies in domestic pigs showed significant and dose-dependent effect of NN9056 on food intake, acceptable tolerability and no histopathological signs of pancreatitis. Sub-chronic treatment in obese Göttingen Minipigs was also well tolerated and accumulated food intake was significantly lower in both treated groups compared to vehicle, with no significant difference between the dose levels of NN9056 $(41.8 \pm 12.6,51.5 \pm 13.8$ and $86.5 \pm 19.5 \mathrm{~kg}$ in high-dose, lowdose and vehicle groups, respectively, $p=0.012$ and $p<0.0001$ for low and high dose vs. vehicle, respectively). Accordingly, there was a weight loss in both treated groups vs. a weight gain in the vehicle group $(-7.2 \pm 4.6 \%,-2.3 \pm$ $3.2 \%$ and $12.3 \pm 3.9 \%$ in the high-dose, low-dose and vehicle groups, respectively, $p<0.0001$ for both vs. vehicle). IVGTT data were not significantly different between groups.

Conclusion NN9056, a long-acting CCK-1 receptor-selective CCK analogue, significantly reduced food intake and BW in obese Göttingen Minipigs after once daily s.c. dosing for 13 weeks.
\end{abstract}

\section{Introduction}

Obesity is an increasing problem worldwide, with a great unmet medical need [1]. Cholecystokinin (CCK) is a

Supplementary information The online version of this article (https:// doi.org/10.1038/s41366-019-0386-0) contains supplementary material, which is available to authorized users.

Trine Ryberg Clausen

TRRS@novonordisk.com

1 Global Drug Discovery, Novo Nordisk A/S, Novo Nordisk Park, 2760 Måløv, Denmark

2 Global Research Technologies, Novo Nordisk A/S, Novo Nordisk Park, 2760 Måløv, Denmark gastrointestinal hormone that could potentially be used as an anti-obesity drug, as evidenced by the lowering of food intake observed after administration to rodents $[2,3]$, pigs [4], monkeys [5] and both lean and obese humans [6, 7]. CCK exists in a number of biologically active forms [8], is mainly secreted from I cells in the upper gastrointestinal tract in response to a meal [9] and has a circulating half-life of $<5 \mathrm{~min}$ [10]. There are two CCK receptors, the CCK-1 receptor and the CCK-2 receptor [11]. The CCK-1 receptor is mainly expressed in the periphery in relation to the gastrointestinal tract, and activation of this receptor induces stimulation of gallbladder contraction, pepsinogen, bile and pancreatic enzyme secretion, relaxation of the sphincter of Oddi, inhibition of gastric emptying and intestinal mobility, and suppression of food intake [12-14]. The CCK-2 receptor is expressed in the stomach where activation 
stimulates gastric acid secretion, in the brain where activation is associated with anxiety and panic attack $[11,12]$ and on the thyroid c cells mediating calcitonin release upon stimulation [15].

The encouraging weight-modulating effects of subchronic CCK-1 receptor agonism observed pre-clinically $[3,16]$ have to date not been reproduced in the clinic. The small-molecule CCK-1 receptor agonist, GI181771X, was explored as an anti-obesity drug, but failed to induce weight loss in obese humans after 24 weeks of treatment [17]. Suboptimal exposure levels and lack of full-day coverage might explain the lack of efficacy. Thus, a peptide-based approach, with a half-life-extending acylation or PEGylation, could be more attractive compared to a small-molecule approach, due to better pharmacokinetic (PK) properties with continuous exposure. Further, higher specificity and fewer off-target effects would be expected with a peptide approach.

Potential safety concerns from treatment with CCK or CCK analogues are pancreatitis mediated by pancreatic and/ or vagal CCK-1 receptors, and anxiety mediated by central CCK-2 receptors. The risk of anxiety may be mitigated by a compound with high selectivity towards the CCK-1 receptor, whereas CCK-1 receptor-mediated pancreatitis remains a risk. However, the prevalence of CCK-1 receptors on the pancreatic acinar cells is species dependent, potentially leading to species differences in the development of pancreatitis as reviewed by Myer et al. [18]. Rodents and dogs are prone to develop pancreatitis after CCK receptor activation $[18,19]$, which may be due to a high level of CCK-1 receptor expression in the exocrine pancreas [20]. In contrast, humans and non-human primates have very low expression of CCK-1 receptors [21, 22], indicating a low risk of CCK-induced pancreatitis.

Based on the available data, it was hypothesised that treatment with a long-acting CCK-1 receptor-selective analogue with 24-h plasma exposure coverage would result in a significant and clinically relevant reduction in food intake and body weight (BW) without causing pancreatitis in humans. The acylated CCK analogue NN9056 is a highly CCK-1 receptor-selective compound with a terminal plasma half-life of approximately $110 \mathrm{~h}$ in young lean minipigs [23]. Due to the high expression of CCK-1 receptors in the pancreas, rodents and dogs were deselected as preclinical efficacy models, leaving pigs and non-human primates as relevant and well-characterised obesity models. For ethical reasons, the obese Göttingen Minipig model was chosen. Female Göttingen Minipigs readily develops obesity when fed ad libitum on chow, and translational value with respect to weight loss has previously been shown with liraglutide [24].

The aim of the present study was to evaluate the effect of NN9056, a novel long-acting and selective CCK-1 receptor agonist, on food intake and BW in obese Göttingen Minipigs. Prior to the sub-chronic study, CCK-1 receptor selectivity, binding and activation by NN9056 were demonstrated in vitro to qualify the pig as a pharmacological model, and acute tolerability and PK were assessed in vivo to enable dose setting in the sub-chronic study.

\section{Methods}

\section{In vitro assays}

\section{CCK receptor binding and activation studies}

CCK analogue NN9056 and sulfated native human CCK-8 was synthesised at Novo Nordisk A/S [23]. All experiments were carried out essentially as previously described [25]. In brief, pig or human CCK receptors were over-expressed in COS-7 cells that were subsequently used for receptorbinding studies or receptor activation studies. Receptor binding was determined using a scintillation proximity assay (SPA) where displacement of radiolabelled CCK- 8 tracer by ligands was determined as a reduction in light emission from the scintillant inside the SPA beads. Receptor activation was assessed using the IP-One homogeneous time-resolved fluorescence assay (Cisbio), where increasing levels of the endogenous second messenger inositol 1 monophosphate (IP1) is measured as a reduction in fluorescence resonance energy transfer between Tb-cryptate-conjugated anti-IP1 antibody and d2-conjugated IP1. Relative receptor affinity $\left(\mathrm{IC}_{50}\right.$ (half-maximal inhibitory concentration)) and potency $\left(\mathrm{EC}_{50}\right.$ (half-maximal effective concentration)) values were calculated in GraphPad Prism v 6.0 (GraphPad software, La Jolla, CA, USA) by nonlinear regression analysis of sigmoidal dose-response curves with constraint on the bottom value to equal that of the reference compound; CCK-8. For the IP-One data, the Hill slope was constrained to be $<0$. All studies were performed in technical duplicate and repeated independently three times $(n=3)$.

\section{CCK-1 receptor in situ hybridisation}

Tissue was fixed in buffered formalin (10\% NBF) and paraffin-embedded (FFPE) according to standard protocols. Tissue blocks were cut at $4.5 \mu \mathrm{m}$ and in situ hybridisation (ISH) was applied using a manual RNAscope single-plex protocol according to the manufacturer's instructions (322310-QKG, Advanced Cell Diagnostics, Hayward, CA, USA). Sections were hybridised with positive control probes PolR2A (polymerase II subunit A, RNAscope probe cat. nos. 3110451, 3124711 and 312481, Advanced Cell Diagnostics, Hayward, CA, USA) and negative control probe DapB (dihydrodipicolinate reductase, RNAscope 
probe cat. no. 310043, Advanced Cell Diagnostics, Hayward, CA, USA). Two consensus probes for the CCK1R were used, one covering mouse and rat (RNAscope probe cat. no. 411521, Advanced Cell Diagnostics, Hayward, CA, USA) and the other covering human, dog and pig (RNAscope ${ }^{\oplus}$ probe cat. no. 411511, Advanced Cell Diagnostics, Hayward, CA, USA).

\section{In vivo studies}

All in vivo studies were conducted in accordance with national regulations in Denmark, which are fully compliant with internationally accepted principles for the care and use of laboratory animals, and with animal experimental licenses granted by the Danish Ministry of Justice. Power calculations for each study type are described in Supplementary Table S1.

\section{Statistical analysis}

All statistical analyses were performed in GraphPad Prism (GraphPad Prism version 6.07 for Windows, GraphPad Software, San Diego, CA, USA) as described below under the individual studies. Normal distribution was assumed for all parameters. When using one-way analysis of variance (ANOVA), a Brown-Forsythe test was used to compare variances in the three groups. In case of unequal variance, a Kruskal-Wallis test followed by Dunn's multiple comparison test was performed. $P$ values below 0.05 were considered statistically significant. Significance levels $p<0.001(* * *)$, $0.01(* *)$ and $0.05(*)$ are indicated in relevant figures.

\section{Dosing solutions}

In the tolerability study in lean domestic pigs (Landrace, Yorkshire Duroc (LYD)), the dosing solutions consisted of $50 \mathrm{mM}$ phosphate, $70 \mathrm{mM}$ sodium chloride and $0.05 \%$ polysorbate 80 with $\mathrm{pH}$ adjusted to 7.4 and NN9056 in concentrations of 0,540 and $5458 \mathrm{nmol} / \mathrm{ml}$. In the acute effect study in lean LYD pigs and in the two studies in obese Göttingen Minipigs, dosing solutions consisted of $8 \mathrm{mM}$ phosphate, $184 \mathrm{mM}$ propylene glycol and $58 \mathrm{mM}$ phenol with pH adjusted to 7.4 and NN9056 in concentrations of $0,424,751,1465,1860$ and $2994 \mathrm{nmol} / \mathrm{ml}$ in the LYD study, $1860 \mathrm{nmol} / \mathrm{ml}$ in the Göttingen Minipig PK study and 0,1902/2198 and $9727 \mathrm{nmol} / \mathrm{ml}$ in the Göttingen Minipig effect study.

\section{Measurement of food intake in lean LYD pigs}

Lean, female LYD pigs (Gundsoegaard, Roskilde, Denmark), approximately 3 months of age weighing approximately 30-35 kg, were used. The animals were fed ad libitum with Danish Top S1 611 (Danish Agro A.m.b.a., Karise, Denmark) and had free access to water. Daily food intake was monitored online by logging the weight of fodder every $15 \mathrm{~min}$ (Mpigwin, Ellegaard Systems, Faaborg, Denmark). Food intake was monitored for up to 3 days prior to compound administration and up to 4 days after administration.

\section{Acute tolerability and adverse pancreas effects in lean LYD pigs}

Animals were allocated into three groups of four animals based on baseline food intake and $\mathrm{BW}$, and dosed subcutaneously (s.c.) with $0.02 \mathrm{ml} / \mathrm{kg}$ to achieve a nominal dose of either 0,10 or $100 \mathrm{nmol} / \mathrm{kg}$. At pre-dose and at $48 \mathrm{~h}$ post-dose, a ethylenediaminetetraacetic acid (EDTA)-stabilised blood sample was taken and plasma concentrations of NN9056, pancreatic lipase, pancreatic $\alpha$-amylase and total bile acids (TBAs) were measured as described in Supplementary Table S2. Pigs were then euthanised by intramuscular (i.m.) injection of $1 \mathrm{ml} / \mathrm{kg}$ Zoletil mixture (Supplementary Table S3), followed by exsanguination by cutting the large arteries to the front legs. Pancreatic tissue was sampled $48 \mathrm{~h}$ after dosing from one pig dosed with $10 \mathrm{nmol} / \mathrm{kg}$ and four pigs dosed with $100 \mathrm{nmol} / \mathrm{kg} \mathrm{NN} 9056$. Tissue samples were fixed in $10 \%$ buffered formalin for approximately $24 \mathrm{~h}$, processed in a tissue processor (Leica ASP300S, Triolab, Brøndby, Denmark), paraffin embedded, cut at $3 \mu \mathrm{m}$ thickness and stained with haematoxylin and eosin (Merck KGaA, Darmstadt, Germany).

Delta values of lipase, $\alpha$-amylase and TBA were compared between the groups using one-way ANOVA with Dunnett's multiple comparison post-test. Daily food intake was compared to vehicle using repeated-measures two-way ANOVA, with "day" and "treatment" as explanatory variables followed by Bonferroni's post-test. Pancreas sections were qualitatively evaluated for signs of pancreatitis.

\section{Acute effect on food intake in lean LYD pigs}

Animals were allocated into one group of three animals (vehicle) and four groups of four animals based on baseline food intake and $\mathrm{BW}$. In the morning on day 0 , the animals were given a s.c. dose of NN9056 or vehicle, and food intake was followed for 4 days. The dosing volume used was $0.025 \mathrm{ml} / \mathrm{kg}$ to achieve nominal doses of $0,10,20,40$ and $80 \mathrm{nmol} / \mathrm{kg}$. In the end of each study, the animals were anaesthetised with Zoletil mixture given i.m. (Supplementary Table S3), and an EDTA-stabilised blood sample was taken from the saphenous vein, before euthanasia. Resulting plasma was stored at $-20{ }^{\circ} \mathrm{C}$ until analysis of plasma NN9056 content as described in Supplementary Table S2.

Statistical comparison of daily food intake between the treated groups and vehicle was done using repeatedmeasures two-way ANOVA, with "day" and "treatment" 
as explanatory variables, followed by Bonferroni's post-test comparing each dosing group to the vehicle group.

\section{Studies in obese Göttingen Minipigs}

These studies were performed in obese, female, ovariectomised (OVX) Göttingen Minipigs (Ellegaard Göttingen Minipigs A/S, Dalmose, Denmark). Obesity had been induced by feeding increasing amounts of SDS minipig diet (SDS, Essex, UK) or Altromin 9023 (Brogaarden, Lynge, Denmark) for at least 10 months before study start. During the studies, the pigs were fed with Altromin 9023 (Brogaarden, Lynge, Denmark) (restricted in the PK study and ad libitum in the effect study) and had free access to water.

\section{PK evaluation in obese Göttingen Minipigs}

The study was performed in three obese Göttingen Minipigs, approximately 2 years of age at study start and with a mean BW ( \pm SD) of $74.5 \pm 8.3 \mathrm{~kg}$ (range: $66.7-83.3 \mathrm{~kg}$ ). The pigs were instrumented with permanent central venous catheters in the cranial caval vein (Cook, C-TPNS-6.5-90-REDO, 6.5 French, Cook Medical, Bjæverskov, Denmark) 3 weeks before study start as previously described [26].

The test compound was given as a s.c. injection $(2.5 \mu \mathrm{L} / \mathrm{kg}$ to achieve a nominal dose of $5 \mathrm{nmol} / \mathrm{kg}$ ) using a NovoPen Echo 4. Blood samples were collected in EDTA-coated tubes at the following time points relative to dosing: predose, $0.083,0.25,0.5,0.75,1,1.5,2,3,4,6,8,10,24,30$, $48,72,96,120,168,192,216,240,264,288,336,360$, $384,408,432$ and $456 \mathrm{~h}$. The resulting plasma was analysed for NN9056 plasma concentration as described in Supplementary Table S2.

One-compartmental PK modelling was performed in Phoenix WinNonlin Professional 6.4 (Pharsight, Mountain View, CA, USA). Data analysis was performed using individual plasma concentration-time values. The given mean values are all geometric means.

\section{Sub-chronic effects on food intake and BW in obese Göttingen Minipigs}

The study was performed in 30 obese Göttingen Minipigs, approximately 18 months of age at study start. After a baseline period of 4 weeks with ad libitum feeding and no treatment, the animals were randomised into three groups. Group 1 was treated s.c. with vehicle $(n=8)$ once daily (QD), Group $2(n=7)$ was treated s.c. with NN9056 QD at a low dose level (regulated from 5 to $2 \mathrm{nmol} / \mathrm{kg}$ ), Group 3 $(n=7)$ was treated s.c. with NN9056 QD at a high dose level $(10 \mathrm{nmol} / \mathrm{kg})$. All groups were treated for 13 weeks, whereafter they were subjected to a 3-week wash-out period.
On study days -8 to $-5,50-51$ and $78-80$, the animals were fasted and anaesthetised for body composition evaluation by dual-energy $\mathrm{x}$-ray absorptiometry scanning. Unfortunately, the measurements were invalid (since a decrease in body fat percentage in the vehicle group was observed, instead of the expected increase typical for this model) and are therefore not included in the Results section, but mentioned here since the food intake data are influenced by the procedure. During the procedure, the animals were anaesthetised with Zoletil mixture i.m. and in addition given an i.m. injection of $0.006-0.01 \mathrm{~mL} / \mathrm{kg}$ Atropine $(1 \mathrm{mg} / \mathrm{ml})$ (Supplementary Table S3).

In the same anaesthesia, on days 78-80, a central venous catheter (BD Careflow 3Fr 200 mm, Argon Medical, TX, USA) was implanted in the jugular vein via an ear vein using a minimally invasive technique. This catheter was used for infusion and for blood sampling.

Measurement of the daily food intake was performed during the entire study period, by logging the weight of fodder online using the MP-2 system (Mbrose Aps, Faaborg, Denmark). BW was obtained twice weekly on a large animal scale during the entire study. Accumulated food intake and BW change from days 1 to 77 were calculated as primary parameters of interest, and statistical comparison between the three groups was done using one-way ANOVA followed by Tukey's multiple comparisons test. In addition, BW loss from baseline was evaluated by comparing BW on days 1 and 77 within each group using two-way ANOVA followed by Sidak's multiple comparisons test.

\section{Glucose tolerance and plasma parameters in obese Göttingen Minipigs}

An intravenous glucose tolerance test (IVGTT) was performed in approx. $18 \mathrm{~h}$ fasted animals after 12 weeks of treatment on study days 84-86. An intravenous glucose bolus of $0.3 \mathrm{~g} / \mathrm{kg}(0.6 \mathrm{~mL} / \mathrm{kg}$ of a sterile $50 \%$ glucose solution, glucose $500 \mathrm{~g} / \mathrm{L}$; SAD) was given through the central venous catheter. Blood samples for glucose and insulin analysis were collected in EDTA tubes $(8 \mathrm{mM})$ with $30 \mu \mathrm{l}$ Aprotinin $(10,000 \mathrm{KIU} / \mathrm{ml}$, Nordic Pharma, Denmark) added to the tubes, at the following time points in relation to the glucose load: predose 1, predose 2 (just before the glucose bolus), 1, 3, 5, 7, 10, 15, $20,25,30,35,40,50$ and $60 \mathrm{~min}$. In addition, a fasting plasma sample of $2 \mathrm{ml}$ was obtained on days $87-88$ for measurement of fasting plasma glucose, insulin, C-peptide, glucagon, leptin, TBA, triglycerides (TG), total cholesterol (TC), amylase and lipase. These blood samples were collected in tubes containing $50 \mu \mathrm{l}$ special stabilisation buffer (Supplementary Table S3). The resulting plasma was pipetted on dry ice and stored at $-20{ }^{\circ} \mathrm{C}$ until analysis. From the IVGTT, $\mathrm{AUC}_{\text {insulin }}$ from 
Table 1 NN9056 binding and activation of porcine and human CCK-1 and CCK-2 receptors

\begin{tabular}{|c|c|c|c|c|c|c|c|c|}
\hline \multirow[b]{3}{*}{ Binding } & \multicolumn{4}{|l|}{ CCK-1 receptor } & \multicolumn{4}{|l|}{ CCK-2 receptor } \\
\hline & \multicolumn{2}{|l|}{ NN9056 } & \multicolumn{2}{|l|}{ CCK-8 } & \multicolumn{2}{|l|}{ NN9056 } & \multicolumn{2}{|l|}{ CCK-8 } \\
\hline & Mean $\mathrm{IC}_{50}(\mathrm{nM})$ & $95 \%$ CI (nM) & Mean $\mathrm{IC}_{50}(\mathrm{nM})$ & 95\% CI (nM) & Mean $\mathrm{IC}_{50}(\mathrm{nM})$ & $95 \% \mathrm{CI}(\mathrm{nM})$ & Mean $\mathrm{IC}_{50}(\mathrm{nM})$ & $95 \% \mathrm{CI}(\mathrm{nM})$ \\
\hline Pig & 0.123 & $0.037-0.406$ & 0.199 & $0.173-0.211$ & $>125^{\mathrm{a}}$ & N/A & 0.102 & $0.039-0.262$ \\
\hline Human & 0.105 & $0.099-0.111$ & 0.203 & $0.137-0.302$ & $>125^{\mathrm{a}}$ & N/A & 1.876 & $0.823-4.277$ \\
\hline Activation & Mean $\mathrm{EC}_{50}(\mathrm{nM})$ & $95 \%$ CI (nM) & Mean $\mathrm{EC}_{50}(\mathrm{nM})$ & $95 \%$ CI (nM) & Mean $\mathrm{EC}_{50}(\mathrm{nM})$ & $95 \%$ CI (nM) & Mean $\mathrm{EC}_{50}(\mathrm{nM})$ & $95 \% \mathrm{CI}(\mathrm{nM})$ \\
\hline Pig & 0.205 & $0.073-0.573$ & 0.221 & $0.146-0.335$ & $>100^{\mathrm{b}}$ & N/A & 0.325 & $0.241-0.438$ \\
\hline Human & 0.093 & $0.059-0.147$ & 0.059 & $0.041-0.085$ & $>100^{\mathrm{b}}$ & N/A & 0.367 & $0.300-0.448$ \\
\hline
\end{tabular}

Data are presented as mean with $95 \%$ CIs, $n=3$

$C I$ confidence interval, $I C_{50}$ half-maximal inhibitory concentration, $E C_{50}$ half-maximal effective concentration

${ }^{\mathrm{a}}$ Mean $\mathrm{IC}_{50}$ is designated as $>125 \mathrm{nM}$ because the $\mathrm{IC}_{50}$ values from the individual experiments were larger than the highest compound dose tested $(125 \mathrm{nM})$ or could not be determined by GraphPad Prism

${ }^{\mathrm{b}} \mathrm{Mean} \mathrm{EC}_{50}$ is designated as $>100 \mathrm{nM}$ because the $\mathrm{EC}_{50}$ values from the individual experiments were larger than the highest compound dose tested $(100 \mathrm{nM})$ or could not be determined by GraphPad Prism

0 to $60 \mathrm{~min}$ and $K_{\mathrm{G}}$ (=negative slope of the linear regression of the natural logarithm to glucose versus time in the time interval from 5 to $30 \mathrm{~min}$ ) were calculated. Fasting plasma parameters, $K_{\mathrm{G}}$ and $\mathrm{AUC}_{\text {insulin }}$ were compared between the three groups using one-way ANOVA followed by Tukey's multiple comparisons test.

On the last dosing day (day 91), a 24-h exposure profile was obtained followed by regular blood samples during the 3 weeks wash-out period, and average 24-h steady-state NN9056 plasma concentrations were calculated.

\section{Analytical procedures}

Plasma concentrations of NN9056 were measured using liquid chromatography mass spectrometry. Further details and description of the bioanalysis for the remaining plasma parameters can be found in Supplementary Table S2.

\section{Data exclusions}

Data exclusions are described in Supplementary Table S1.

\section{Results}

\section{In vitro studies}

\section{In vitro binding and activity of NN9056 on porcine and human CCK-1 and CCK-2 receptors}

Whereas the CCK receptor subtypes share only $\sim 50 \%$ homology, they are highly conserved across species. The human and pig orthologues of the CCK-1 and CCK-2 receptors share $83 \%$ and $91 \%$ amino acid identity, respectively (UniProt).

As summarised in Table 1, the relative affinity of NN9056 towards the porcine and human CCK-1 receptors was highly similar, also in comparison with the reference compound CCK-8. Furthermore, as opposed to the strong binding observed with $\mathrm{CCK}-8$ on porcine and human $\mathrm{CCK}$ 2 receptors, no $\mathrm{IC}_{50}$ values for NN9056 could be determined at the concentrations tested, indicating high CCK-1 receptor selectivity of NN9056 in both species.

Functionally, NN9056 displayed relative potency at picomolar concentrations on both porcine and human CCK1 receptors, comparable to the activity seen with CCK-8 (Table 1). As expected, CCK-8 also potently activated the CCK-2 receptor, whereas NN9056 activation occurred only weakly at the highest concentration tested (100 nM), again indicating that the CCK-1 receptor selectivity of NN9056 is preserved in both species.

Taken together, these in vitro data indicate that the pig qualifies as a relevant animal model for pharmacological studies of NN9056.

\section{ISH for the CCK-1 receptor in mouse, rat, dog, pig and human}

The ISH analyses showed that the CCK-1 receptor messenger RNA (mRNA) expression level in the pancreatic acinar cells was species specific, with high expression observed in the mouse and rat, medium expression in the dog and low expression in the pig and human (see Supplementary Fig. S1). The low CCK-1 receptor mRNA expression in the pig is comparable to the level seen in humans, and predicts a low risk of CCK-1 mediated pancreatitis. 


\section{In vivo studies}

Acute tolerability and adverse pancreas effects in lean LYD pigs

All animals dosed with $100 \mathrm{nmol} / \mathrm{kg}$ NN9056 had subdued behaviour $2 \mathrm{~h}$ post dosing. Three animals had increased respiration (from 50-60 respirations/min to 80-96 respirations/min), warm skin (no fever) and no appetite for snacks. CCK molecules are known for the ability to cause nausea and vomiting, and the subdued behaviour observed could potentially be a sign of nausea, but since no vomiting occurred no firm conclusion could be drawn regarding this. From $11 \mathrm{~h}$ post dosing, none of the animals had any clinical signs. Food intake was significantly reduced $(86 \pm 4 \%$ (corresponding to $-1.1 \pm 0.1 \mathrm{~kg}$ ) from 0 to $24 \mathrm{~h}$ and $75 \pm 3 \%$ (corresponding to $-0.8 \pm 0.03 \mathrm{~kg}$ ) from 25 to $48 \mathrm{~h}$, compared to vehicle $(p<$ 0.001 for both). Plasma concentration of NN9056 was $555 \pm$ $36.4 \mathrm{nM}$ after $48 \mathrm{~h}$ in the treated animals.

No clinical signs were observed in animals dosed with $10 \mathrm{nmol} / \mathrm{kg} \mathrm{NN9056}$ and food intake was not significantly reduced ( $22 \pm 5 \%$ (corresponding to $-0.3 \pm-0.1 \mathrm{~kg}$ ) from 0 to $24 \mathrm{~h}$ and $33 \pm 7 \%$ (corresponding to $-0.4 \pm 0.1 \mathrm{~kg}$ ) from 25 to $48 \mathrm{~h}$ ) compared to vehicle. Plasma concentration of NN9056 was $43.0 \pm 1.6 \mathrm{nM}$ after $48 \mathrm{~h}$ in the treated animals.

Pancreatic tissue from one pig dosed with $10 \mathrm{nmol} / \mathrm{kg}$ and four pigs dosed with $100 \mathrm{nmol} / \mathrm{kg}$ NN9056 were microscopically evaluated and no histopathological changes suggestive of pancreatitis were observed in any of the samples (data not shown). In all animals exposed to NN9056, pancreatic lipase, pancreatic $\alpha$-amylase and TBA were measured in plasma pre-dose (basal) and post-dose. No significant differences were seen pre- or post-dose between NN9056-treated animals and vehicle-treated animals (Supplementary Table S4).

\section{Acute effect on food intake in lean LYD pigs}

Food intake was dose dependently reduced after a single s.c. dose of 10, 20, 40 or $80 \mathrm{nmol} / \mathrm{kg}$ NN9056 (Fig. 1). NN9056 of 20 and $40 \mathrm{nmol} / \mathrm{kg}$ significantly reduced food intake for 2 days and of $80 \mathrm{nmol} / \mathrm{kg}$ significantly reduced food intake for at least 4 days (Fig. 1). The plasma concentration of NN9056, measured 4 days after dosing, were $22.6 \pm 4.5$, $39.7 \pm 17.1,86.2 \pm 6.9$ and $206 \pm 17.2 \mathrm{nM}$ in the $10,20,40$ and $80 \mathrm{nmol} / \mathrm{kg}$ dosing groups, respectively.

\section{PKs of NN9056 in obese Göttingen Minipigs}

PK parameters were evaluated using a one-compartment model with first-order absorption and first-order elimination (no lag time), which fitted well to the experimental data. Key PK parameters are shown in Table 2, and the plasma

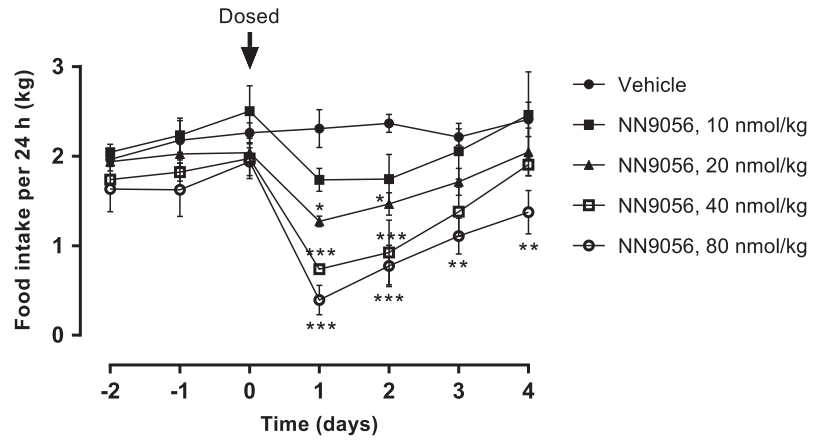

Fig. 1 Mean daily food intake $(\mathrm{kg})$ after a single subcutaneous (s.c.) dose of vehicle, 10, 20, 40 and $80 \mathrm{nmol} / \mathrm{kg}$ NN9056 in lean LYD pigs. $n=3$ for vehicle and $40 \mathrm{nmol} / \mathrm{kg}, n=4$ for the others, mean \pm SEM. Food intake compared using repeated-measures two-way analysis of variance (ANOVA), with "day" and "treatment" as explanatory variables, followed by Bonferroni's post-test comparing each dosing group to the vehicle group. ${ }^{*} p<0.05,{ }^{*} p<0.01, * * * p<0.001$

Table 2 Primary pharmacokinetic parameter estimates from the onecompartmental pharmacokinetic analysis in obese Göttingen Minipigs after subcutaneous dosing of NN9056

\begin{tabular}{ll}
\hline Parameter (unit) & Value geometric mean [min;max] \\
\hline$T_{\max }(\mathrm{h})$ & $3.4[2.7 ; 5.3]$ \\
$C_{\max }(\mathrm{pmol} / \mathrm{L})$ & $76,775[66294 ; 90714]$ \\
AUC/dose $(\mathrm{h} * \mathrm{~kg} / \mathrm{L})$ & $3091[3000 ; 3275]$ \\
$t_{1 / 2}(\mathrm{~h})$ & $128[107 ; 146]$ \\
$\mathrm{K} 01(1 / \mathrm{h})$ & $1.6958[0.9997 ; 2.2927]$ \\
$\mathrm{K} 10(1 / \mathrm{h})$ & $0.005435[0.004763-0.006492]$ \\
$\mathrm{V} / \mathrm{F}(\mathrm{L} / \mathrm{kg})$ & $0.05952[0.05134-0.06983]$ \\
$\mathrm{Cl} / \mathrm{F}(\mathrm{L} / \mathrm{h} / \mathrm{kg})$ & $0.000323[0.000305 ; 0.000333]$ \\
\hline
\end{tabular}

$t_{1 / 2}$ terminal half-life, $K 01$ absorption rate constant, $K 10$ elimination rate constant

concentration-time curves are shown in Supplementary Fig. S2.

\section{Sub-chronic effects on food intake and BW in obese Göttingen Minipigs}

Overall, treatment with NN9056 was well tolerated. During the study, one animal from the NN9056 low-dose group was euthanised on day 85 due to respiratory distress and circulatory failure unrelated to the test compound.

The accumulated food intake was decreased in all treated groups compared to vehicle, but with no differences between the two NN9056 groups $(41.8 \pm 12.6,51.513 .8$ and $86.5 \pm 19.5 \mathrm{~kg}$ in high-dose, low-dose and vehicle groups, respectively, $p<0.001$ vs. vehicle) (Fig. 2). In parallel with this, there was a BW loss in both the treated groups vs. a BW gain in the vehicle group $(-7.2 \pm 4.6,-2.3 \pm 3.2$ and $12.3 \pm 3.9 \%$ in the high-dose, low-dose and vehicle groups, respectively, $p<0.001$ vs. vehicle), again with no significant difference between the two NN9056 groups (Fig. 

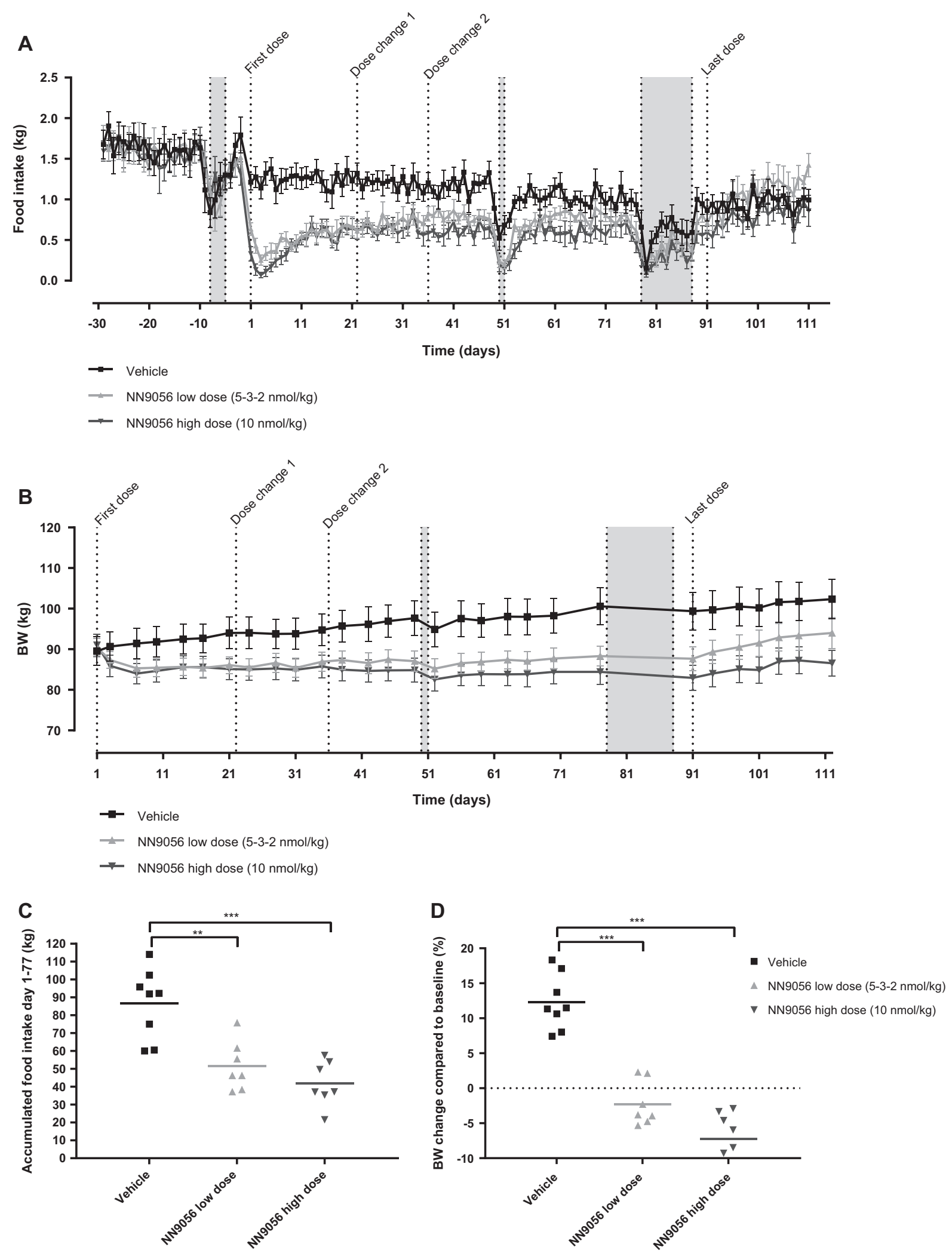

2). The BW change from baseline from days 1 to 77 within each group showed a significant weight increase in the vehicle group ( $89.5 \pm 10.0$ vs. $100.6 \pm 12.8 \mathrm{~kg}, p<0.001)$, a non-significant weight loss in the low-dose group (90.4 \pm 6.2 vs. $88.3 \pm 6.6 \mathrm{~kg}$ ) and a significant weight loss in the highdose group $(91.0 \pm 7.2$ vs. $84.4 \pm 8.1 \mathrm{~kg}, p<0.001)$. 
Fig. 2 Mean daily food intake (a), body weight (BW) development (b), accumulated food intake from days 1 to 77 (c) and BW change from days 1 to 77 in obese Göttingen Minipigs dosed subcutaneously (s.c.) with either vehicle (black $\square, n=8$ ), NN9056 low-dose group (light grey $\mathbf{\Delta}, n=7$ ) or NN9056 high-dose group (dark grey $\boldsymbol{\nabla}, n=$ 7). Data are presented as mean \pm SEM. BW change and accumulated food intake was compared by one-way analysis of variance (ANOVA) followed by Tukey's multiple comparisons test. $* * p<0.01$, *** $p<$ 0.001 . Grey shading: Periods with anaesthesia/fasting due to dualenergy x-ray absorptiometry (DEXA) scanning or metabolic tests. Dose change 1: dose change from 5 to $3 \mathrm{nmol} / \mathrm{kg}$ in the low-dose group. Dose change 2: dose change from 3 to $2 \mathrm{nmol} / \mathrm{kg}$ in the lowdose group

\section{Glucose tolerance and plasma parameters in obese Göttingen Minipigs}

During the IVGTT, no significant differences were found between the groups in either glucose clearance $\left(K_{\mathrm{G}}\right)(3.4 \pm$ $1.2,4.1 \pm 2.1$ and $3.0 \pm 0.6 \mathrm{~min}^{-1}$ in high-dose, low-dose and vehicle groups, respectively) or $\mathrm{AUC}_{\text {insulin }}(52.0 \pm 8.9$, $48.9 \pm 22.7$ and $72.7 \pm 28.3 \mathrm{nM} * \min$ in high-dose, low-dose and vehicle groups, respectively), although $\mathrm{AUC}_{\text {insulin }}$ tended to be decreased in the two NN9056 groups compared to vehicle (Fig. 3). This indicates a slight improvement in insulin sensitivity, most likely secondary to the weight loss. No statistical analysis was done on glucagon data due to many of the values being below lower level of quantification for the assay (data not shown).

No significant differences between the groups were found in any of the fasting plasma parameters (glucose, insulin, Cpeptide, glucagon, total glucagon-like peptide-1 (GLP-1), TBA, leptin, TG, TC, $\alpha$-amylase and lipase) (Table 3).

Steady-state NN9056 plasma concentration showed an approximate 6-fold difference between the two dose groups (Table 3). Exposure during the 3-week wash-out period is shown in Supplementary Fig. S2.

\section{Discussion}

The present study examined the effect of the long-acting and highly CCK-1 receptor-selective CCK analogue, NN9056, on food intake and BW in obese Göttingen Minipigs.
A

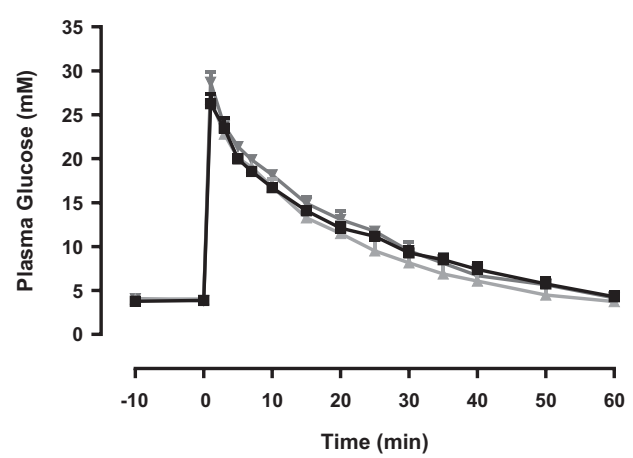

C

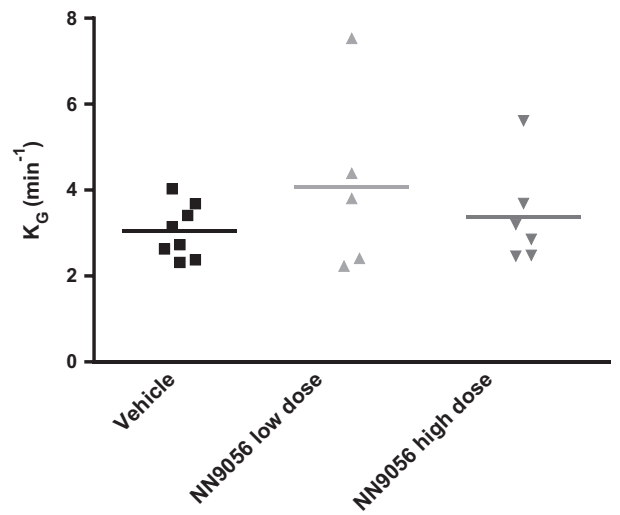

B

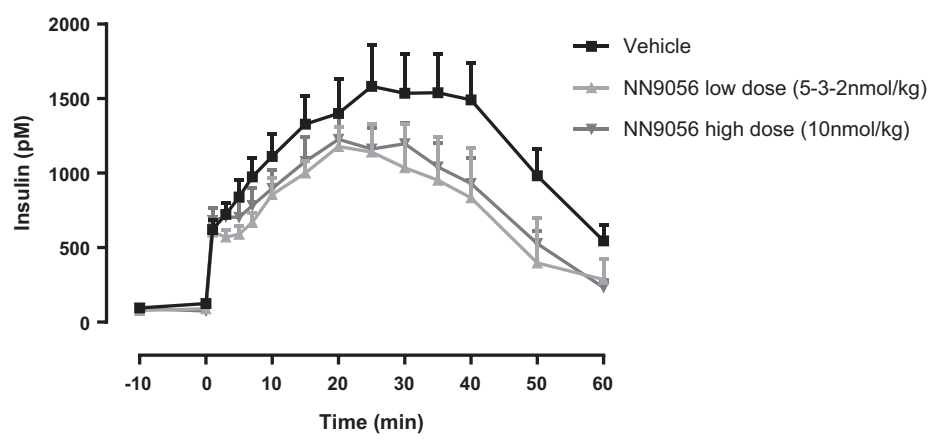

D

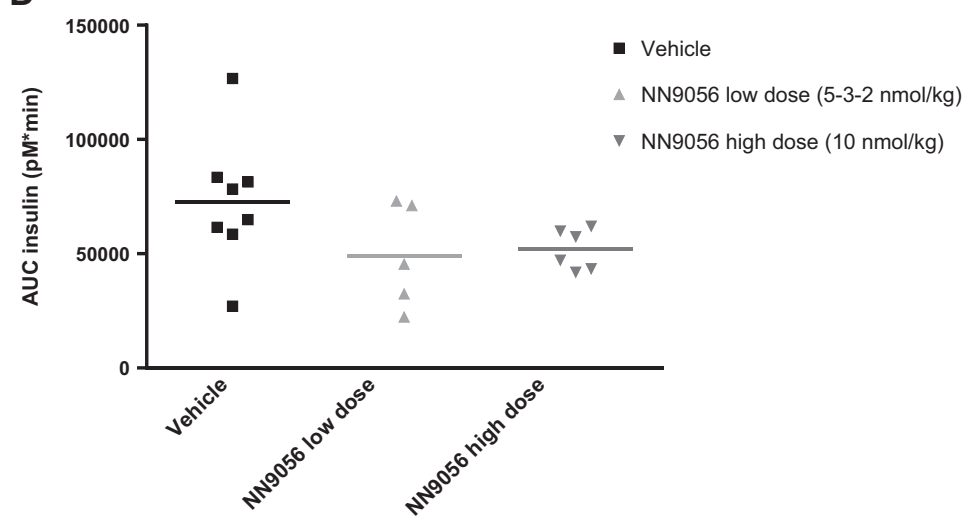

grey $\nabla)$. Data are presented as mean \pm SEM, $n=5-8 . K_{\mathrm{G}}$ and $\mathrm{AUC}_{\mathrm{insulin}}$ were compared between the groups using one-way analysis of variance (ANOVA) followed by Tukey's multiple comparisons test. $p=$ non-significant for all
Fig. 3 Mean plasma glucose (a), mean plasma insulin (b), $K_{\mathrm{G}}(\mathbf{c})$ and $\mathrm{AUC}_{\text {insulin }}$ (d) during intravenous glucose tolerance test (IVGTT) in obese Göttingen Minipigs following an IVGTT performed after 12 weeks of subcutaneous (s.c.) treatment with either vehicle (black $\square$ ), NN9056 low dose (light grey $\mathbf{A}$ ) and NN9056 high dose (dark 
Table 3 Metabolic parameters in obese Göttingen minipigs evaluated after $12^{1 / 2}$ weeks of s.c. treatment with either vehicle, NN9056 low dose or NN9056 high dose

\begin{tabular}{|c|c|c|c|}
\hline Parameter & Vehicle & $\begin{array}{l}\text { NN9056 } \\
\text { low dose }\end{array}$ & $\begin{array}{l}\text { NN9056 } \\
\text { high dose }\end{array}$ \\
\hline Glucose (mM) & $4.1 \pm 0.4$ & $4.0 \pm 0.2$ & $4.0 \pm 0.2$ \\
\hline Insulin $(\mathrm{pM})^{\mathrm{a}}$ & $136 \pm 80$ & $78 \pm 20$ & $68 \pm 9^{*}$ \\
\hline C-peptide (pM) & $47 \pm 28$ & $24 \pm 10$ & $24 \pm 2$ \\
\hline Glucagon (pM) & $11.6 \pm 3.9$ & $13.5 \pm 9.1$ & $11.6 \pm 2.3$ \\
\hline Total GLP-1 (pM) & $34.6 \pm 9.7$ & $37.1 \pm 9.8$ & $37.6 \pm 12.3$ \\
\hline TBA $(\mu \mathrm{M})$ & $6.7 \pm 3.6$ & $7.8 \pm 3.2$ & $9.0 \pm 3.4$ \\
\hline TG (mM) & $0.63 \pm 0.35$ & $50.56 \pm 0.21$ & $0.41 \pm 0.10$ \\
\hline $\mathrm{TC}(\mathrm{mM})$ & $2.3 \pm 0.48$ & $32.1 \pm 0.49$ & $2.1 \pm 0.59$ \\
\hline Leptin $(\mathrm{ng} / \mathrm{ml} \mathrm{HE})^{\mathbf{a}}$ & $42.7 \pm 11.5$ & $538.6 \pm 13.3$ & $47.2 \pm 13.3$ \\
\hline$\alpha$-Amylase (U/L) & $1570 \pm 235$ & $1568 \pm 430$ & $1755 \pm 404$ \\
\hline Lipase (U/L) & $8.8 \pm 2.1$ & $12.5 \pm 7.4$ & $9.4 \pm 1.6$ \\
\hline $\begin{array}{l}\text { Average NN9056 conc. (nM) } \\
\text { during the } 24 \text { h profile }\end{array}$ & NA & $175 \pm 35$ & $1130 \pm 18$ \\
\hline
\end{tabular}

The groups were compared using one-way ANOVA followed by Tukey's multiple comparisons test (Kruskal-Wallis followed by Dunn's multiple comparison test for insulin). ${ }^{*} p<0.05$, all other $p$ values were non-significant. For C-peptide there was a significant treatment related trend $(p<0.05)$

$G L P-1$ glucagon-like peptide-1, $T B A$ total bile acid, $T G$ triglycerides, $T C$ total cholesterol, $H E$ human equivalent, ANOVA analysis of variance, NA not available

${ }^{\mathrm{a}}$ Data are presented as mean plus or minus $\mathrm{SD}, n=5-8$

Results from in vitro receptor-binding and activation assays indicated highly comparable relative affinities and potencies of NN9056 for pig and human CCK receptors. Combined with a low pancreatic expression of CCK-1 receptor mRNA, acceptable acute in vivo tolerability and lack of histopathological signs of pancreatitis after a single, high dose of NN9056 in lean LYD pigs, this confirmed the pig as a relevant model for evaluation of pharmacodynamic effects of CCK analogues. This was further substantiated by a dose dependent acute reduction in food intake of NN9056 in lean LYD pigs.

Consequently, 5 and $10 \mathrm{nmol} / \mathrm{kg}$ of NN9056 was dosed once daily in obese Göttingen Minipigs to estimate the effective dose and exposure levels in an obesity model. Both dose levels led to an immediate and significant reduction in food intake, but since the effect on food intake was essentially the same in the two dose groups, the lowdose group was decreased first to $3 \mathrm{nmol} / \mathrm{kg}$ and then to $2 \mathrm{nmol} / \mathrm{kg}$, in order to try to obtain differentiation between the two dose levels. Although dose differentiation was achieved, the total accumulated food intake in the two dose groups was not significantly different, and thus maximal efficacy seemed to be obtained after once daily dosing of $3-5 \mathrm{nmol} / \mathrm{kg}$. The reduced food intake lead to a small decrease in BW in both dose groups, which was significantly different from the quite substantial BW gain observed in the vehicle group. These data are in contrast to previously reported efficacy data of a small-molecule CCK1 receptor agonist showing no effect on BW in obese humans [17]. The lack of efficacy in that study could be related to insufficient exposure, but it has also been proposed to be due to a sub-optimal trial design, with strict caloric restriction preventing the primary appetite-reducing effect to be observed [27]. The half-life of NN9056 was around $130 \mathrm{~h}$ in the obese Göttingen Minipigs, and thus full 24-h plasma exposure coverage was obtained throughout the study. This may, together with the ad libitum feeding regime, be part of the explanation for the significant and sustained effect on food intake and BW obtained with this CCK analogue.

In contrast to the anti-diabetic effects reported in rodents [3], there were no significant effects on plasma glucose in the Göttingen Minipigs, which could be due to the fact that they are not hyperglycemic (Table 3). However, insulin resistance is present in the model (Christoffersen B, 2018, Insulin resistance in the obese Göttingen Minipig model, personal communication), and a trend for lower fasting insulin and lower insulin secretion during the IVGTT in the NN9056treated groups compared to vehicle was observed, indicating improved insulin sensitivity secondary to the weight loss.

Treatment with NN9056 was well tolerated, but pathological effects on the pancreas after sub-chronic dosing cannot be completely excluded, since pancreas histology was only evaluated after a single high dose in lean LYD pigs. In contrast, the older, obese Göttingen Minipigs were treated subchronically and furthermore seemed to be more sensitive to the treatment than the young LYD pigs as a $10 \mathrm{nmol} / \mathrm{kg}$ dose gave a much stronger effect in the obese Göttingen Minipigs compared to the LYD pigs (Figs. 1 and 2). This difference between the two pig strains may be due to both exposure differences and differences in sensitivity. However, the lack of severe clinical signs, together with lipase and amylase levels within the normal range, indicate that pancreatitis was not an issue even at the exposure levels obtained in the obese Göttingen Minipigs (an average plasma concentration of approx. $1100 \mathrm{nM}$ in the high-dose group).

In conclusion, NN9056, a long-acting CCK-1 receptorselective analogue, was well tolerated and significantly reduced food intake and BW in obese Göttingen Minipigs during a 13-week study. NN9056 holds a promising potential as monotherapy for obesity or in combination with other appetite-regulating peptides.

Acknowledgements From Citoxlab Denmark, Marianne Kronborg Bracken is thanked for skilful study direction and veterinary support during the in-life phase of the study. From Novo Nordisk A/S, Kamilla Larsen, Johnny Kaltoft Nisted, Ann-Charlott Kemp, Chalotte Lasak Krøyer Pedersen, Lotte Schmidt Marcher, Inge Rubach, Pernille 
Kristiane Pedersen, Anders Hagedal Uhrenfeldt and Hanne Toftelund are thanked for excellent technical assistance in relation to study conduct. Gitte Kølander Hansen and Annette Hansen are thanked for performing the leptin analysis and the in vitro assays, respectively. Hanne Skov Pedersen, Kirsten Lenskjold Henriksen, Susanne Halkier and Annette Koch Larsen are thanked for performing the plasma analysis of glucagon, c-peptide, GLP-1 (total) and insulin. Sara Bay Fitzwilliams is thanked for performing the NN9056 plasma analysis.

\section{Compliance with ethical standards}

Conflict of interest All authors are or were employees at Novo Nordisk A/S when the work was done, and most are minor shareholders in Novo Nordisk A/S.

Publisher's note: Springer Nature remains neutral with regard to jurisdictional claims in published maps and institutional affiliations.

Open Access This article is licensed under a Creative Commons Attribution 4.0 International License, which permits use, sharing, adaptation, distribution and reproduction in any medium or format, as long as you give appropriate credit to the original author(s) and the source, provide a link to the Creative Commons license, and indicate if changes were made. The images or other third party material in this article are included in the article's Creative Commons license, unless indicated otherwise in a credit line to the material. If material is not included in the article's Creative Commons license and your intended use is not permitted by statutory regulation or exceeds the permitted use, you will need to obtain permission directly from the copyright holder. To view a copy of this license, visit http://creativecommons. org/licenses/by/4.0/.

\section{References}

1. WHO. Obesity and overweight: key facts [Webpage]. Geneva: World Health Organisation; 2018. http://www.who.int/newsroom/fact-sheets/detail/obesity-and-overweight. Updated $16 \mathrm{Feb}$ 2018; cited 7 Oct 2018.

2. Gibbs J, Young RC, Smith GP. Cholecystokinin decreases food intake in rats. J Comp Physiol Psychol. 1973;84:488-95.

3. Irwin N, Frizelle P, O'Harte FPM, Flatt PR. Metabolic effects of activation of CCK receptor signaling pathways by twice-daily administration of the enzyme-resistant CCK-8 analog, (pGluGln)-CCK-8, in normal mice. J Endocrinol. 2013;216:53-9.

4. Baldwin BA, Cooper TR, Parrott RF. Effect of cholecystokinin octapeptide on food intake in pigs. Proc Nutr Soc. 1982;41:119-21.

5. Gibbs J, Falasco JD, McHugh PR. Cholecystokinin-decreased food intake in rhesus monkeys. Am J Physiol Legacy Content. 1976;230:15-8.

6. Stacher G. Satiety effects of cholecystokinin and ceruletide in lean and obese man. Ann NY Acad Sci. 1985;448:431-6.

7. MacIntosh CG, Morley JE, Wishart J, Morris H, Jansen JBMJ, Horowitz M, et al. Effect of exogenous cholecystokinin (CCK)-8 on food intake and plasma CCK, leptin, and insulin concentrations in older and young adults: evidence for increased CCK activity as a cause of the anorexia of aging. J Clin Endocrinol Metab. 2001;86:5830-7.

8. Johnsen AH. Phylogeny of the cholecystokinin/gastrin family. Front Neuroendocrinol. 1998;19:73-99.

9. Buffa R, Solcia E, Go VL. Immunohistochemical identification of the cholecystokinin cell in the intestinal mucosa. Gastroenterology. 1976;70:528-32.
10. Lilja P, Fagan CJ, Wiener I. Infusions of pure cholecystokinin in humans. Correlation between plasma concentrations of cholecystokinin and gallbladder size. Gastroenterology. 1982;83(1 II):256-61.

11. Noble F, Wank SA, Crawley JN, Bradwejn J, Seroogy KB, Hamon $\mathrm{M}$, et al. International Union of Pharmacology. XXI. Structure, distribution, and functions of cholecystokinin receptors. Pharmacol Rev. 1999;51:745-81.

12. Dufresne M, Seva C, Fourmy D. Cholecystokinin and gastrin receptors. Physiol Rev. 2006;86:805-47.

13. Rehfeld JF. Clinical endocrinology and metabolism. Cholecystokinin. Best Pract Res Clin Endocrinol Metab. 2004;18:569-86.

14. Little TJ, Horowitz M, Feinle-Bisset C. Role of cholecystokinin in appetite control and body weight regulation. Obes Rev. 2005;6:297-306.

15. Erdogan MF, Gursoy A, Kulaksizoglu M. Long-term effects of elevated gastrin levels on calcitonin secretion. J Endocrinol Invest. 2006;29:771-5.

16. Moran TH, Sawyer TK, Seeb DH, Ameglio PJ, Lombard MA, McHugh PR. Potent and sustained satiety actions of a cholecystokinin octapeptide analogue. Am J Clin Nut. 1992;55:286S-90S.

17. Jordan J, Greenway FL, Leiter LA, Li Z, Jacobson P, Murphy K, et al. Stimulation of cholecystokinin-A receptors with GI181771X does not cause weight loss in overweight or obese patients. Clin Pharmacol Ther. 2007;83:281-7.

18. Myer JR, Romach EH, Elangbam CS. Species- and Dose-specific pancreatic responses and progression in single- and repeat-dose studies with GI181771X: a novel cholecystokinin 1 receptor agonist in mice, rats, and monkeys. Toxicol Pathol. 2014;42:260-74.

19. Simpson KW, Beechey-Newman N, Lamb CR, Smyth JB, Hughes G, Coombe K, et al. Cholecystokinin-8 induces edematous pancreatitis in dogs associated with short burst of trypsinogen activation. Dig Dis Sci. 1995;40:2152-61.

20. Monstein HJ, Nylander AG, Salehi A, Chen D, Lundquist I, Hakanson R. Cholecystokinin-A and cholecystokinin-B/gastrin receptor mRNA expression in the gastrointestinal tract and pancreas of the rat and man. A polymerase chain reaction study. Scand J Gastroenterol. 1996;31:383-90.

21. Ji B, Bi Y, Simeone D, Mortensen RM, Logsdon CD. Human pancreatic acinar cells lack functional responses to cholecystokinin and gastrin. Gastroenterology. 2001;121:1380-90.

22. Holicky EL, Hadac EM, Ding XQ, Miller LJ. Molecular characterization and organ distribution of type A and B cholecystokinin receptors in cynomolgus monkey. Am J Physiol Gastrointest Liver Physiol. 2001;281:G507-14.

23. Sensfuss U, Kruse T, Skyggebjerg RB, Uldam HK, Vestergaard B, Huus K, et al. Structure-activity relationships and characterization of highly selective, long acting, peptide-based cholecystokinin 1 receptor (CCK-1R) agonists. J Med Chem. 2019;62:1407-19.

24. Raun K, von Voss P, Knudsen LB. Liraglutide, a once-daily human glucagon-like peptide-1 analog, minimizes food intake in severely obese minipigs. Obesity. 2007;15:1710-6.

25. Bugge A, Jansen PG, Maria L, Sanni SJ, Clausen TR. Cloning and characterization of the porcine gastrin/cholecystokinin type 2 receptor. Eur J Pharmacol. 2018;833:357-63.

26. Christoffersen B, Ribel U, Raun K, Golozoubova V, Pacini G. Evaluation of different methods for assessment of insulin sensitivity in Gottingen minipigs: introduction of a new, simpler method. Am J Physiol Regul Integr Comp Physiol. 2009;297:R1195-201.

27. Roses AD. Stimulation of cholecystokinin-A receptors with Gl181771X: a failed clinical trial that did not test the pharmacogenetic hypothesis for reduction of food intake. Clin Pharmacol Ther. 2009;85:362-5. 